\title{
KADAR LOGAM BERAT Pb, Cd DAN KELIMPAHAN PERIFITON PADA EKOSISTEM LAMUN DI TELUK JEPARA
}

\author{
The Heavy Metal Content of $\mathrm{Pb}, \mathrm{Cd}$ and The Abundance of Periphyton \\ on Seagrass Ecosystems in the Gulf of Jepara
}

\section{Himatul Aliyah Febriana, Pujiono Wahyu Purnomo*), Suryanti}

\author{
Program Studi Manajemen Sumberdaya Perairan, Departemen Sumberdaya Akuatik \\ Fakultas Perikanan dan Ilmu Kelautan, Universitas Diponegoro \\ Jl. Prof. Soedarto, SH, Tembalang, Semarang, Jawa Tengah - 50275, Telp/Fax. +6224 7474698 \\ Email : himatulaliyahf@gmail.com
}

\begin{abstract}
ABSTRAK
Ekosistem padang lamun merupakan ekosistem yang memiliki produktivitas primer yang tinggi, hal tersebut didukung oleh keberadaan perifiton yang melekat pada permukaan daun lamun. Pengaruh tersebut dapat berkurang akibat adanya kegiatan perikanan atau aktivitas antropogenik yang menyebabkan pencemaran kandungan logam berat seperti $\mathrm{Pb}$ dan $\mathrm{Cd}$. Tujuan penelitian adalah untuk mengetahui jenis lamun, kelimpahan perifiton dan kandungan logam berat pada daun lamun serta hubungan kelimpahan perifiton dengan kandungan logam berat di Teluk Jepara. Penelitian ini menggunakan metode deskriptif. Penelitian dilaksanakan pada bulan Maret - April 2016 di Teluk Jeparapada lingkungan lamun padat (368 ind $\left./ \mathrm{m}^{2}\right)$, sedang $\left(240 \mathrm{ind} / \mathrm{m}^{2}\right)$, dan jarang $\left(178 \mathrm{ind} / \mathrm{m}^{2}\right)$. Sampling menggunakan metode purposive random sampling dengan menentukan obyek yang diambil sebagai sampel berdasarkan kerapatan lamun. Jenis lamun yang ditemukan di Teluk Jepara adalah Thalassia sp. Rata-rata kelimpahan perifiton pada kerapatan lamun padat, sedang dan jarang adalah 1742 $\mathrm{ind} / \mathrm{cm}^{2}, 1481 \mathrm{ind} / \mathrm{cm}^{2}$, dan $1249 \mathrm{ind} / \mathrm{cm}^{2}$. Perifiton yang ditemukan dari kelas Bacillariophyceae, Cyanophyceae, Euglenophyceae, Rodhophyceae, Dinophyceae dan Chlorophyceae. Hasil logam berat $\mathrm{Pb}$ dan $\mathrm{Cd}$ selama tiga kali sampling diperoleh nilai yang sama yaitu $\mathrm{Pb} \leq 100 \mathrm{mg} / \mathrm{gr}$ dan $\mathrm{Cd} \leq 10 \mathrm{mg} / \mathrm{gr}$ Berdasarkan hasil penelitian disimpulkan bahwa adanya kandungan logam berat $\mathrm{Pb}$ dan $\mathrm{Cd}$ tidak mempengaruhi keberadaan perifiton pada daun lamun di perairan Teluk Jepara.
\end{abstract}

Kata kunci: Lamun; Perifiton; Logam Berat Pb dan Cd; Teluk Jepara

\section{ABSTRACT}

Seagrass ecosystem is one of the ecosystems that has high primary productivity, supported by the presence of periphyton which attached to the seagrass leaf surface. The influence can less result of fishing activity or anthropogenic activities can also cause contamination of heavy metals like a $\mathrm{Pb}$ and $\mathrm{Cd}$. The purpose of this research were to determine the type of seagrass, the abundance of perifiton and heavy metal content in the seagrass leaves and relationship periphyton abundance to the heavy metal content in the Gulf of Jepara. This research uses descriptive method. Research activities carried out arround March-April 2016 in the Gulf of Jepara in dense seagrass environment (368 ind/ $\left.\mathrm{m}^{2}\right)$, moderate $\left(240 \mathrm{ind} / \mathrm{m}^{2}\right)$, dan rare $\left(178 \mathrm{ind} / \mathrm{m}^{2}\right)$. Determining location of sampling using purposive random sampling method to determine the object sampled by different densities of the seagrass. Seagrass species found in the Gulf of Jepara is Thalassia sp. The average abundance of periphyton in dense, medium and rare seagrass density are $1742 \mathrm{ind} / \mathrm{cm} 2,1481 \mathrm{ind} / \mathrm{cm} 2$, and 1249 ind/cm2. Periphyton types were found came from class of Bacillariophyceae, Cyanophyceae, Euglenophyceae, Rodhophyceae, Dinophyceae and Chlorophyceae. The result of heavy metals $\mathrm{Pb}$ and Cd for three times of the sampling obtained similar content of heavy metals which are $\mathrm{Pb} \leq 100 \mathrm{mg} / \mathrm{gr}$ and $\mathrm{Cd} \leq 10 \mathrm{mg} / \mathrm{gr}$. Based on the research results concluded that content of $\mathrm{Pb}$ and $\mathrm{Cd}$ heavy metals is not affect the existence periphyton on leaves of seagrass in the Gulf waters Jepara.

Key Words: Seagrass; Periphyton; Heavy Metal of Pb and Cd; Gulf of Jepara

*) Penulis penanggungjawab

\section{PENDAHULUAN}

Salah satu faktor yang mendukung kehidupan ekosistem lamun di wilayah ini adalah kondisi morfologi partai dan kondisi perairan. Dalam hal ini diketahui bahwa teluk Jepara dikategorikan sebagai wilayah teluk dengan tipe battimetri yang datar dengan substrat dasar berupa campuran karang, pasir dan lumpur, sehingga memungkinkan lamun tumbuh dengan baik untuk terikat dengan dasar perairan. Ekosistem padang lamun merupakan ekosistem yang memiliki keanekaragaman hayati dan memiliki produktivitas primer yang tinggi di

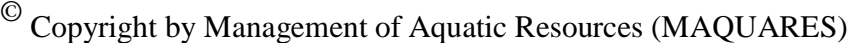


daerah laut dangkal. Tingginya produktifitas primer di ekosistem lamun didukung oleh keberadaan perifiton yang tumbuh pada daunnya. Adanya kegiatan perikanan atau aktivitas antropogenik lainnya di sekitar Teluk Jepara dapat menyebabkan pencemaran salah satunya adalah adanya kandungan logam berat.

Perifiton adalah bagian dari trofic level yang memiliki peranan baik secara langsung ataupun tidak langsung dalam ekosistem lamun. Diatom perifiton merupakan indikator biologi yang baik untuk mengetahui tingkat pencemaran yang terjadi pada suatu badan air (Wibowo et. al., 2014). Atas dasar hal tersebut maka kajian mengenai organisme perifiton memiliki peranan penting dalam mendiskripsikan ekosistem perairan laut dangkal di Teluk Jepara, terlebih bila hal ini dikaitkan dengan adanya potensi cemaran logam berat $\mathrm{Pb}$ (timbal) dan $\mathrm{Cd}$ (cadmium). Unsur $\mathrm{Pb}$ dan $\mathrm{Cd}$ merupakan komponen logam berat yang berbahaya di lingkungan perairan laut dangkal khususnya di Teluk Jepara. Menurut Lestari dan Edward (2004) Cd merupakan salah satu logam berat yang bersifat racun dan merugikan bagi semua organisme hidup, bahkan juga berbahaya untuk manusia.

Tujuan dilakukannya penelitian ini adalah untuk mengetahui: (1) mengetahui jenis dan kerapatan lamun di Teluk Jepara; (2) mengetahui kelimpahan perifiton dan kandungan logam berat yang berada pada daun lamun di Teluk Jepara; (3) mengetahui hubungan kelimpahan perifiton dan kandungan logam berat di Teluk Jepara.

\section{MATERI DAN METODE PENELITIAN}

\section{A. Materi penelitian}

Materi dalam penelitian ini adalah perifiton dan logam berat $\mathrm{Pb}$ dan $\mathrm{Cd}$ yang menempel pada daun lamun lamun di Teluk Jepara. Peralatan yang digunakan adalah GPS (Global Positioning System), line transek, secchi disc, bola arus, stopwatch, refraktometer, termometer, kertas indikator $\mathrm{Ph}$, kamera digital, DO meter, botol BOD winkler 250, mikroskop, sedgwick rafter, pipet tetes, botol reagen, kantong plastik, masker dan snorkel, alat tulis, buku identifikasi perifiton. Bahan yang digunakan untuk penelitian ini adalah formalin $4 \%, \mathrm{MnSO}_{4} \mathrm{dan}$ $\mathrm{NaOH}$ dalam KI H2SO4, Na2S2O3, amilum, dan aquades.

\section{B. Metode penelitian}

Penelitian ini dilakukan pada bulan Maret-April 2016, di Teluk Jepara. Analisa Laboratorium untuk uji logam berat dilakukan di Balai Besar Teknologi Pencegahan Pencemaran Industri (BBTPPI), Semarang dan identifikasi perifiton dilakukan di Laboratorium Pengelolaan Sumberdaya dan Ilmu Lingkungan (PSDIL) Universitas Diponegoro, Semarang. Metode yang digunakan dalam penelitian ini adalah dengan pendekatan survei, yaitu penelitian dilakukan berdasarkan data yang dipelajari dari data sampel yang diambil dari populasi, sehingga ditemukan kejadian-kejadian relatif, distribusi, dan hubungan-hubungan antar variabel. Metode pendekatan survei ini bersifat deskriptif karena penelitian ini juga membahas variabel-variabel lain yang berhubungan dengan permasalahan faktor-faktor yang mempengaruhinya (Gulo, 2005 dalam Prakoso, 2015).

\section{Metode sampling}

\section{a) Penentuan lokasi sampling}

Teknik sampling dilakukan dengan metode Purposive Random Sampling yaitu teknik pengambilan sampel yang digunakan apabila sampel yang akan diambil memilki pertimbangan tertentu (Fachrul, 2007). Pengambilan sampel dilakukan pada 3 stasiun yang berbeda yaitu stasiun I pada bagian dengan kerapatan Lamun padat, stasiun II pada bagian kerapatan Lamun sedang, dan stasiun III kerapatan Lamun jarang.

\section{b) Metode pengambilan sampel lamun}

Sampel diambil dari tiap titik sampling pada transek yang telah ditentukan dengan frame kuadran. Tiap titik sampling diambil tegakan lamun dari tiga kuadran dengan lima kali ulangan. Pengambilan sampel lamun untuk periphytonnya dilakukan dengan cara mengambil 5 tanaman secara acak dari tiap titik sampling, sedangkan pengambilan sampel uji logam berat $\mathrm{Pb}$ dan $\mathrm{Cd}$ diambil sebanyak kira-kira 6 gr, kemudian menutupnya dengan kantong plastik dan segera menyegelnya, untuk kemudian ditransportasikan ke laboratorium.

\section{c) Metode pengambilan perifiton}

Periphyton dipisahkan dari daun lamun dengan perendaman dalam larutan asam asetat $4 \%$ selama 2 jam, untuk memudahkan pengerokan. Kemudian dilakukan pengerokan permukaan daun lamun, lalu lapisan sampel dimasukkan dalam botol berlabel yang berisi formalin 4\% sebanyak 100 ml (Ott, 1990 dalam Jaya, 2005).

\section{d) Proses analisis kandungan logam berat lamun}

Prosedur analisis kandungan logam berat Pb menggunakan acuan SNI 066992.3-2004 dan Cd SNI 066992.4-2004. Sampel lamun dikeringkan dengan menggunakan oven pada suhu $100^{\circ} \mathrm{C}$ selama 45 menit. Selanjutnya ditumbuk hingga halus. Sampel yang akan diuji ditimbang sebanyak $\pm 3,00 \mathrm{~g}$ kemudian dimasukan ke dalam Erlenmayer dan ditambahkan $25 \mathrm{ml}$ aquades kemudian diaduk dengan batang pengaduk. Sampel ditambahkan 5-10 $\mathrm{ml} \mathrm{HNO}_{3}$ pekat dan diaduk hingga bercampur rata dan ditutup dengan kaca arloji kemudian dipanaskan dengan suhu yang telah diatur yaitu $105^{\circ} \mathrm{C}-120^{\circ} \mathrm{C}$. Larutan dipanaskan sampai volume tinggal 10 $\mathrm{ml}$, kemudian diangkat dan didinginkan. Larutan ditambahkan $5 \mathrm{ml} \mathrm{HNO}_{3}$ pekat tetes demi tetes kemudian larutan kembali dipanaskan di hot plate hingga timbul asap putih dan larutan sampel menjadi jernih. Selanjutnya sampel didinginkan dan disaring dengan kertas saring Whattman. Filtrat sampel dimasukkan ke dalam labu ukur $100 \mathrm{ml}$ dan ditambahkan aquades sampai tepat tanda batas. Kemudian sampe siap diukur dengan menggunakan AAS (Atomic Absorption Spectrophotometry) (Pratiwi et. al., 2011). 
Analisis Data

1. Indeks Keanekaragaman (H')

Indeks yang digunakan dalam mengetahui tingkat keragaman jenis dalam suatu komunitas yaitu menggunakan indeks keanekaragaman (Odum, 1971):

$\mathrm{H}^{\prime}=-\Sigma \mathrm{Pi} \ln \mathrm{Pi}$

$P i=\frac{n i}{N}$

Keterangan:

$\mathrm{H}^{\prime}=$ Indeks keanekaragaman jenis

$\mathrm{Pi}=$ proporsi spesies $\mathrm{ke}-\mathrm{i}(\mathrm{ni} / \mathrm{N})$

$\mathrm{ni}=$ Jumlah individu jenis ke-i

$\mathrm{N}=$ Jumlah total individu

2. Indeks Keseragaman Jenis (E)

Indeks keseragaman ini digunakan untuk mengetahui berapa besar kesamaan penyebaran sejumlah individu setiap genus pada tingkat komunitas. Indeks keseragaman berdasarkan persamaan Odum (1971) adalah sebagai berikut:

$e=\frac{H^{\prime}}{\operatorname{Ln} S}$

Keterangan:

$\mathrm{e}=$ Indeks keseragaman

$\mathrm{H}^{\prime}=$ Indeks keanekaragaman

$\mathrm{S}=$ Jumlah jenis

3. Indeks Dominasi (D)

Indeks Dominasi dihitung berdasarkan indeks Shimpson (1949) dalam Dianthani (2003) dengan rumus sebagai berikut:

$\nu=\sum \frac{n i^{2}}{N}$

Keterangan:

$\mathrm{D}=$ Indeks dominasi simpson

$\mathrm{ni}=$ Jumlah individu jenis ke-i

$\mathrm{N}=$ Jumlah total individu

4. Kelimpahan Relatif (KR)

Indeks ini menerangkan proporsi jumlah individu suatu jenis dengan jumlah individu sesuai jenis. Kelimpahan relatif (KR), dihitung dengan rumus :

$K R=\frac{\pi i}{N} \times 100 \%$

Keterangan :

$\mathrm{KR}=$ Kelimpahan relatif

$\mathrm{ni}=$ Jumlah jenis ke-i

$\mathrm{N}=$ Jumlah total individu seluruh jenis

\section{HASIL DAN PEMBAHASAN}

A. Hasil

a) Keadaan umum lokasi sampling

Teluk Jepara adalah pantai pesisir utara Jawa yang terletak di Kabupaten Jepara, Jawa Tengah. Kabupaten Jepara memiliki potensi sumberdaya pesisir yang besar ditinjau dari keberadaan garis pantainya lebih dari 72 $\mathrm{km}$. Kegiatan yang terdapat pada lokasi penelitian adalah adanya kegiatan perikanan seperti nelayan, selain itu juga berdekatan dengan dermaga dan sungai-sungai di sekitar lokasi penelitian. Teluk ini juga sebagai habitat rumput laut, dimana pada musim tertentu rumput laut sangat banyak tumbuh di kawasan ini. Lokasi penelitian yang terletak di Teluk Jepara bagian utara merupakan daerah padang lamun yang penyebarannya tidak merata yang dicirikan oleh substratnya banyak pasir dan pecahan karang. Pada lokasi penelitian terdapat beberapa perahu nelayan yang dikaitkan pada kayu pancang dan ditemukan biota-biota yang berasosiasi dengan lamun, dintaranya adalah ikan, moluska, krustasea.

\section{b) Kelimpahan dan Komposisi Lamun}

Hasil pengamatan pada lokasi penelitian ditemukan 1 jenis lamun yaitu jenis Thalassia. Untuk lebih jelasnya data kelimpahan lamun di perairan Pantai Bandengan dapat dilihat pada tabel 1 sebagai berikut : 
Tabel 1: Keanekaragaman, keseragaman, dan kelimpahan lamun di Teluk Jepara

\begin{tabular}{|c|c|c|c|c|c|c|c|}
\hline \multirow[t]{2}{*}{ No } & \multirow[t]{2}{*}{ Jenis } & \multicolumn{2}{|l|}{ padat } & \multicolumn{2}{|l|}{ sedang } & \multicolumn{2}{|l|}{ jarang } \\
\hline & & ni (ind $\left./ \mathbf{m}^{2}\right)$ & KR (\%) & ni (ind $\left./ \mathrm{m}^{2}\right)$ & KR (\%) & $\begin{array}{l}\text { ni } \\
\text { (ind } / \mathrm{m}^{2} \text { ) }\end{array}$ & KR (\%) \\
\hline 1. & Thalassia $s p\left(\mathrm{ind} / \mathrm{m}^{2}\right)$ & 368 & 100 & 240 & 100 & 178 & 100 \\
\hline & Total (ind $\left./ 5 \mathrm{~m}^{2}\right)$ & 1840 & 100 & 1200 & 100 & 890 & 100 \\
\hline & $\mathrm{H}^{\prime}$ & 0 & & 0 & & 0 & \\
\hline & $\mathrm{e}$ & 0 & & 0 & & 0 & \\
\hline
\end{tabular}

c) Jenis dan kelimpahan periphyton pada lamun (Thalassia)

Perifiton yang ditemukan diperoleh dengan cara melakukan pengerokan pada permukaan daun lamun.

Hasil perhitungan kelimpahannya adalah seperti ditunjukkan pada tabel 2 berikut:

Tabel 2. Kelimpahan prifiton pada kerapatan lamun

\begin{tabular}{cccc}
\hline Stasiun & \multicolumn{3}{c}{$\begin{array}{c}\text { Kerapatan Lamun } \\
\text { (ind/cm2) }\end{array}$} \\
\cline { 3 - 4 } Waktu (minggu) & Padat & Sedang & Jarang \\
\cline { 2 - 4 } I & 1710 & 1258 & 1173 \\
II & 1117 & 1907 & 1383 \\
III & 2398 & 1278 & 1192 \\
\hline Rata-rata & 1742 & 1481 & 1249 \\
\hline
\end{tabular}

Berdasarkan analisis kelimpahan perifiton seperti terlihat pada tabel diatas menunjukkan bahwa terdapat kecenderungan yang meningkat dengan peningkatan kerapatan lamun. hasil analisis ragam terhadap kelimpahan perifiton antar lamun menunjukkan bahwa tidak terdapat perbedaan antar kawasan lamun yang tertempel $(\alpha>$ 0,05 ) dimana $\mathrm{F}$ hitung sebesar 0,975 dan $\mathrm{F}$ tabel sebesar 5,143. Adapun kelimpahan perifiton pada setiap pengamatannya disajikan dalam gambar dibawah ini:

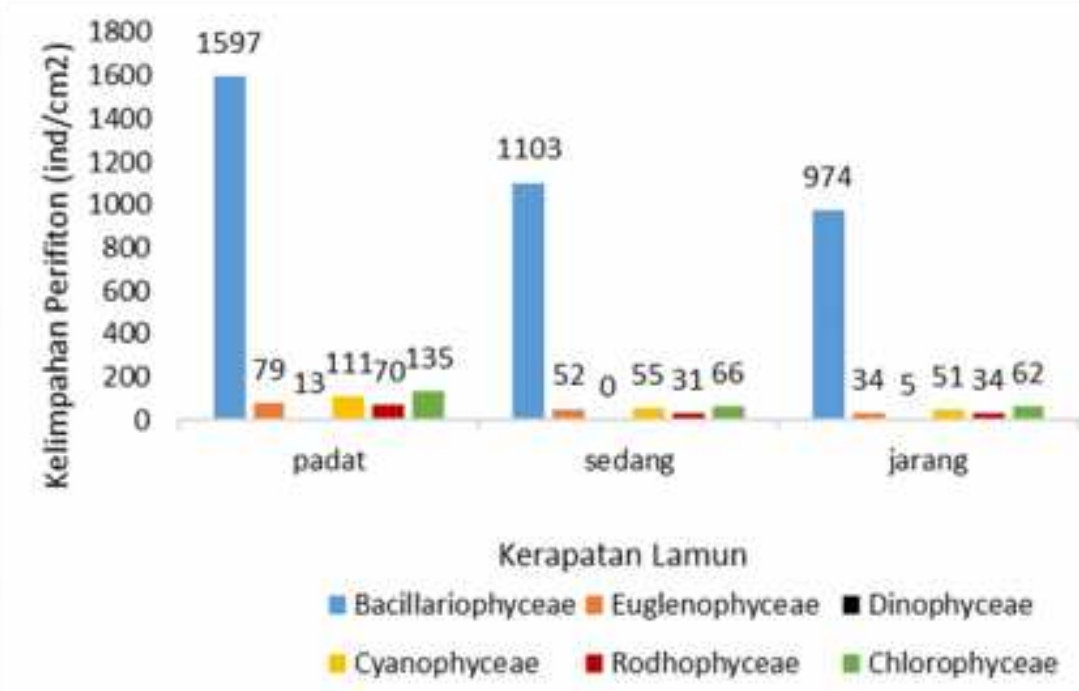

Gambar 1. Histogram rata-rata kelimpahan perifiton

- Berdasarkan gambar diatas terlihat bahwa rata-rata kelimpahan perifiton berdasarkan tingkat kerapatan lamun yang paling banyak ditemukan adalah dari kelas Bacillariophyceae.

d) Struktur Komunitas Perifiton pada Lamun

Berdasarkan hasil perhitungan, struktur komunitas yang terdiri dari indeks kenekaragaman, indeks keseragaman dan indeks dominasi maka rata-rata dari indeks tersebut disajikan dalam tabel dibawah ini:

Tabel 3. Rerata Struktur komunitas perifiton

\begin{tabular}{lccc}
\hline Struktur Komunitas & \multicolumn{3}{c}{$\begin{array}{c}\text { Struktur komunitas perifiton } \\
\text { pada kerapatan lamun }\end{array}$} \\
\cline { 2 - 4 } & padat & Sedang & jarang \\
\hline Keanekaragaman $\left(\mathrm{H}^{\prime}\right)$ & 2,548 & 2,421 & 2,249 \\
Keseragaman (e) & 0,866 & 0,843 & 0,794 \\
Dominasi (D) & 0,104 & 0,119 & 0,148 \\
\hline
\end{tabular}




\section{e) Kandungan Logam Berat $\mathrm{Pb}$ dan $\mathrm{Cd}$}

Berdasarkan uji logam berat pada daun lamun dengan menggunakan AAS, maka diperoleh nilai rata-rata logam berat $\mathrm{Pb}$ dan $\mathrm{Cd}$ pada sampling pertama sampai sampling ketiga adalah sebagai berikut:

Tabel 4. Kandungan logam berat $\mathrm{Pb}$ dan $\mathrm{Cd}$

\begin{tabular}{llccc}
\hline No & Parameter $(\mathbf{m g} / \mathbf{g r})$ & padat & Sedang & jarang \\
\hline 1 & Timbal $(\mathrm{Pb})$ & $<100$ & $<100$ & $<100$ \\
2 & Kadmium $(\mathrm{Cd})$ & $<10$ & $<10$ & $<10$ \\
\hline Sumber: & Penelitian 2016 & &
\end{tabular}

Sumber: Penelitian 2016

f) Hubungan kelimpahan perifiton dengan kandungan logam berat

Hubungan antara kelimpahan perifiton dengan kandungan logam berat $\mathrm{Pb}$ pada sampling pertama di Teluk Jepara tersaji dalam gambar berikut:

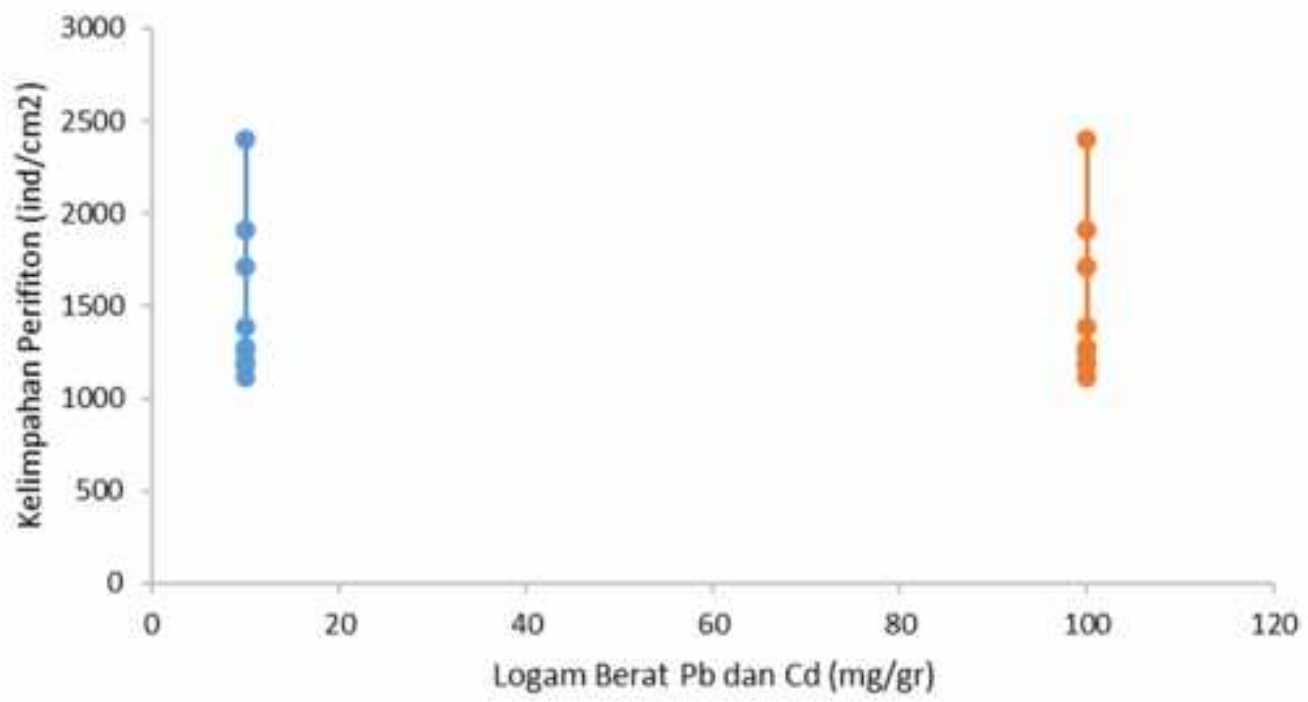

Gambar 2. Hubungan kelimpahan perifiton dengan logam berat $\mathrm{Pb}$ dan $\mathrm{Cd}$

Berdasarkan grafik diatas diperoleh keterangan bahwa kandungan logam berat $\mathrm{Pb}$ dan $\mathrm{Cd}$ tidak mempengaruhi peningkatan kelimpahan perifiton.

g) Parameter lingkungan

Data rata-rata hasil pengukuran peubah fisika dan kimia perairan beserta kisaran nilai optimumnya dicantumkan pada Tabel 1 berikut ini

Tabel 5. Rata-rata hasil pengukuran parameter oceanografi di Teluk Jepara

\begin{tabular}{|c|c|c|c|c|c|c|}
\hline \multirow{2}{*}{ Parameter } & \multirow{2}{*}{ Satuan } & \multicolumn{3}{|l|}{ Sampling } & \multirow{2}{*}{$\begin{array}{l}\text { Nilai } \\
\text { optimum }\end{array}$} & \multirow{2}{*}{ Pustaka } \\
\hline & & Ke-1 & Ke-2 & $\mathrm{Ke}-3$ & & \\
\hline Suhu air & ${ }^{\circ} \mathrm{C}$ & 30 & 31 & 30 & $28-30$ & Dahuri, 2003 \\
\hline Salinitas & $\% o$ & 33 & 33 & 33 & $10-40$ & Dahuri, 2003 \\
\hline Kec. Arus & $\mathrm{m} /$ detik & 0,032 & 0,045 & 0,051 & $0,025-0,050$ & Mason, 1981 \\
\hline Kecerahan & $\mathrm{m}$ & Sampai dasar & Sampai dasar & $\begin{array}{l}\text { Sampai } \\
\text { dasar }\end{array}$ & $\begin{array}{l}\text { Sampai } \\
\text { dasar }\end{array}$ & Tuwo, 2011 \\
\hline Kedalaman & $\mathrm{Cm}$ & 77 & 71 & 72 & $\mathrm{sd} 20 \mathrm{~m}$ & Alongi, 1998 \\
\hline $\mathrm{pH}$ & & 7 & 8 & 8 & 8 & Alongi, 1998 \\
\hline DO & $\mathrm{mg} / \mathrm{l}$ & 5,6 & 6 & 5,6 & Minimum 3 & Pescod, 1973 \\
\hline
\end{tabular}

Peubah fisika dan kimia merupakan hal penting yang berpengaruh terhadap variabel-variabel hayati yang diukur dalam penelitian. Dari di atas dapat dilihat bahwa parameter lingkungannya masih dalam kisaran optimum kondisi perairan.

\section{B. Pembahasan}

Berdasarkan hasil penelitian yang tersaji pada tabel Lamun yang ditemukan terdapat 1 jenis lamun dari famili Hydrocharitaceae yaitu spesies Thalassia sp dengan jmlah tegakan yang berbeda. Berdasarkan Tabel 1 di atas, Thalassia sp ditemukan di ketiga stasiun pengamatan, pada stasiun A dengan kerapatan padat terdapat 368 (ind $\left./ \mathrm{m}^{2}\right)$, di stasiun B dengan kerapatan sedang terdapat $240\left(\mathrm{ind} / \mathrm{m}^{2}\right)$, di stasiun $\mathrm{C}$ dengan kerapatan jarang

\footnotetext{
${ }^{\text {C }}$ Copyright by Management of Aquatic Resources (MAQUARES)
} 
terdapat $178\left(\mathrm{ind} / \mathrm{m}^{2}\right)$. Lamun yang ditemukan tumbuh di substrat berpasir karena bagian timur dari Teluk Jepara memiliki substrat pasir. Beberapa lamun juga ditemukan hidup berasosiasi dengan terumbu karang yang ada di Teluk Jepara. Hal ini sesuai dengan pernyataan Prasetya et. al, (2015) spesies lamun yang biasanya tumbuh dengan vegetasi tunggal adalah Thalassia hemprichii, Enhalus acoroides, Halophila ovalis, Halodule uninervis, Cymodocea serrulata, dan Thalassodendron ciliatum. Padang lamun tumbuh dengan baik di daerah yang terlindung dan substrat pasir yang stabil, serta dekat sedimen yang bergerak secara horizontal. Pada daerah dimana terjadi bioturbasi yang tinggi akibat aktivitas organisme bentik seperti udang, molusca, dan cacing, maka kepadatan populasi lamun dan komunitas pionir cenderung berkurang. Jenis Thalassia sp ini merupakan jenis pionir (pelopor) yang secara alami banyak tumbuh pada daerah terbuka pasang surut dan merupakan jenis dominan yang tersebar merata di kawasan jepara dan memiliki perakaran yang kuat dibandingkan jenis lamun yang lainnya.

Hasil indeks keanekaragaman lamun di Teluk Jepara dengan kerapatan yang berbeda yaitu padat, sedang dan jarang masing - masing adalah 0. Menurut Shanon-Wiener (Kreb,1989) dalam Herfina et. al., (2014), menyatakan dimana bila $0<\mathrm{H}^{\prime} \leq 1$ maka keanekaragaman rendah, dan bila $1<\mathrm{H}^{\prime} \leq \mathfrak{3}$ maka keanekaragaman sedang, sedangkan bila H'>3 maka keanekaragaman tinggi. Hal ini menunjukkan bahwa keanekaragaman lamun yang ada di Teluk Jepara adalah rendah. Hasil indeks keseragaman lamun di Teluk Jepara dengan kerapatan yang berbeda yaitu padat, sedang dan jarang masing - masing adalah 0. Hal ini menjukkan bahwa lamun yang ada di Teluk Jepara memiliki keseragaman yang rendah, berarti tidak banyak ragamnya. Hal ini diperkuat oleh Herfina et. al., (2014), bahwa bila e mendekati 0 (nol) maka, spesies penyusun tidak banyak ragamnya, ada dominasi antara spesies tertentu, bila e mendekati 1(satu), jumlah individu yang dimiliki oleh spesies tidak jauh berbeda, tidak ada dominasi antar spesies tertentu.

Sampling 1, 2 dan 3 baik pada kerapatan lamun padat, sedang maupun jarang, kelas Bacillariohyceae menunjukan komposisi tertinggi. Hal ini dikarenakan Bacillariophyceae merupakan organisme bentik perintis dalam perairan. Tingginya kelimpahan perifiton dari kelas Bacillariophyceae dikarenakan kelas Bacillariophyceae merupakan jenis diatom yang paling toleran terhadap kondisi perairannya sehingga dapat berkembang biak dengan cepat. Menurut Arman dan Supriyanti (2007) perkembangan jenis Perifiton lebih banyak ditemukan jenis Bacillariohyceae. yang merupakan jenis perintis bagi komunitas Perifiton, sedangkan pada tahap selanjutnya semakin banyak ditemukan organisme Perifiton lainnya seperti Rotifera, Nematoda dan Crustacea.

Terkait dengan keberadaan perifiton pada daun lamun, maka Schubert (1984) dalam Mayasari (2008) menambahkan bahwa eksistensi diatom dapat pula dipergunakan sebagai indikator kualitas air dimana mereka hidup. Sebagai contoh Navicula dan Nitzchia yang merupakan indikator perairan yang dihuninya sudah tercemar. Berdasarkan hasil yang diperoleh (Tabel 3) rata-rata kelimpahan Perifiton pada kerapatan Lamun padat adalah 1742 ind/cm2, pada kerapatan lamun sedang rata-rata kelimpahan perifiton adalah 1481 ind/cm2. Sedangkan pada kerapatan lamun jarang adalah $1249 \mathrm{ind} / \mathrm{cm} 2$.

Hasil penelitian memperlihatkan bahwa baik pada kerapatan lamun rapat, sedang maupun jarang menunjukkan kesamaan penempelannya. Fenomena ini diperkirakan disebabkan karena arus yang melalui kawasan lamun relatif stabil dan seragam sehingga peluang perifiton untuk dapat terperangkap pada seluruh daun lamun baik rapat, sedang maupun jarang mempunyai peluang yang sama. Hal ini dijelaskan oleh Barus (2014) bahwa kecepatan arus merupakan faktor penting bagi organisme perifiton, dimana makin tinggi kecepatan arus maka semakin cepat organisme perifiton terlepas dari substratnya sehingga mempengaruhi kelimpahan dan distribusi dari perifiton tersebut. Susanti (2000) dalam Yuniarno (2015) menambahkan bahwa arus mampu menyeleksi beberapa grup dari spesies perifiton sehingga berpengaruh terhadap tipe komunitas organisme tersebut.

Secara umum struktur komunitas perifiton pada kerapatan lamun padat, sedang dan jarang di perairan Teluk Jepara menggambarkan kondisi yang stabil, hal ini dindikasikan dengan indeks keanekaragaman yang tergolong sedang, indeks keseragaman yang relatif sama (merata) dan indeks dominansi yang rendah atau tidak ada jenis yang mendominasi. Hal ini terlihat dari komposisi genera perifiton tidak adanya jenis yang mendominasi pada waktu sampling pertama, kedua dan ketiga. Hampir semua jenis perifiton keberadaannya selalu hadir pada kerapatan lamun padat, sedang dan jarang pada waktu pengamatan. Beberapa faktor dapat menjadi pertimbangan untuk menjelaskan fenomena perkembangan komunitas perifiton ini, antara lain faktor oseanografi, waktu pengambilan sampel.

Berdasarkan hasil uji dengan menggunakan analisis AAS, kandungan logam berat $\mathrm{Pb}$ dan $\mathrm{Cd}$ di Teluk Jepara diperoleh hasil logam berat $\mathrm{Pb}$ sebesar $\leq 100 \mathrm{mg} / \mathrm{gr}$ pada ketiga sampling baik pada kerapatan padat, sedang maupun jarang. Begitu juga dengan kandungan logam berat $\mathrm{Cd}$ diperoleh nilai yang sama pada kerapatan lamun padat, sedang, dan jarang yaitu sebesar $\leq 10 \mathrm{mg} / \mathrm{gr}$ dari ketiga sampling yaitu sampling pertama, kedua dan ketiga. Secara umum hasil penelitian ini menunjukkan bahwa kadar logam berat $\mathrm{Pb}$ maupun $\mathrm{Cd}$ pada lamun mempunyai nilai yang cukup tinggi dibandingkan dengan standart baku mutu air untuk biota laut yaitu $8 \mathrm{mg} / \mathrm{gr}$ dan $1 \mathrm{mg} / \mathrm{gr}$ (KMNLH Nomor 51 Tahun 2004). Hal ini menunjukkan bahwa kandungan logam berat $\mathrm{Pb}$ dan $\mathrm{Cd}$ pada lamun sudah tercemar. Kadar $\mathrm{Pb}$ maupun $\mathrm{Cd}$ yang terdapat pada perairan Teluk Jepara menunjukkan hasil yang lebih tinggi dari baku mutu air laut yang ditetapkan oleh KMNLH Nomor 51 Tahun 2004. Hal tersebut 
berpotensi menimbulkan pencemaran lingkungan. Hasil kandungan logam berat $\mathrm{Pb}$ dan $\mathrm{Cd}$ yang tinggi diperkirakan disebabkan oleh pengaruh masuknya cemaran dari beberapa sungai yang bermuara di wilayah Teluk Jepara.

Berdasarkan Gambar 4 diperoleh hasil bahwa adanya kandungan logam berat $\mathrm{Pb}$ dan $\mathrm{Cd}$ tidak mempengaruhi keberadaan perifiton pada daun lamun di perairan Teluk Jepara. Kelimpahan perifiton di perairan ini melimpah, tetapi di sisi lain dengan adanya keberadaan logam berat yang tinggi pada perairan ini menyebabkan berkurangnya kualitas perairan tersebut, sehingga keberadaan perifiton dalam ekosistem lamun menjadi kurang produktif. Mengingat bahwa organisme pefiton mempunyai peranan penting dalam penyedia produktivitas perairan, karena dapat melakukan proses fotosintesis yang dapat membentuk zat organik dari zat anorganik. Organisme ini juga memanfaatkan nutrien yang ada di ekosistem lamun.

Logam $\mathrm{Pb}$ dan $\mathrm{Cd}$ dapat menyebabkan pengurangan kandungan klorofil dalam plankton. Konsentrasi $\mathrm{Pb}$ dan Cd yang tinggi dapat merusak bagian kloroplas. Menurut Arunakumara dan Zhang (2009), kerusakan kloroplas dapat menyebabkan kerusakan pada pigmen fotosintesis yang dimana kebanyakan disebabkan oleh toksisitas logam $\mathrm{Cd}$. Logam $\mathrm{Pb}$ juga dapat terikat sehingga memperburuk fungsi routing pada plankton sehingga aktivitas fotosintesis terganggu dan dan menghalangi pertumbuhan atau matinya sel-sel dalam jaringan. Kandungan logam berat yang meningkat pada air laut dan sedimen akan masuk ke dalam sistem rantai makanan dan berpengaruh pada kehidupan organisme (Said et al., 2009). Peningkatan kadar logam berat pada air laut akan mengakibatkan logam berat yang semula dibutuhkan untuk berbagai proses metabolisme dapat berubah menjadi racun bagi organisme laut (Rochyatun et. al., 2006).

\section{KESIMPULAN}

Berdasarkan penelitian yang telah dilakukan dengan judul "Kadar Logam Berat Pb, Cd dan Kelimpahan Perifiton di Teluk Jepara", bahwa kesimpulan yang diperoleh adalah sebagai berikut: Jenis lamun yang ditemukan pada lokasi penelitian yaitu Thalassia sp. Kerapatan lamun pada kerapatan padat, sedang dan jarang berturut-turut adalah $368 \mathrm{ind} / \mathrm{m}^{2}, 240 \mathrm{ind} / \mathrm{m}^{2}$, dan $178 \mathrm{ind} / \mathrm{m}^{2}$. Kelimpahan perifiton pada kerapatan lamun padat (1742 ind/cm2), sedang (1481 ind/cm2), dan jarang (1249 ind/cm2), sedangkan kandungan logam berat $\mathrm{Pb}$ adalah $<100 \mathrm{mg} / \mathrm{gr}$ dan $\mathrm{Cd}$ adalah $<10 \mathrm{mg} / \mathrm{gr}$. Hubungan antara logam berat $\mathrm{Pb}$ dan $\mathrm{Cd}$ dengan kelimpahan perifiton adalah adanya kandungan logam berat $\mathrm{Pb}$ dan $\mathrm{Cd}$ tidak mempengaruhi peningkatan kelimpahan perifiton di perairan Teluk Jepara.

\section{DAFTAR PUSTAKA}

Alongi, D. M. 1998. Coastal Ecosystem Process. CRC. Press. New York.

Arman, E dan S. Supriyanti. 2007. Struktur Komunitas Perifiton pada Subtrat Kaca di Lokasi Pemeliharaan Kerang Hijau (Perna viridis) di Perairan Teluk Jakarta. Jurnal Hidrosfir., 1(2): 67-74.

Arunakumara, K.K.I.U and Zhang, X. 2009. Effect of Heavy Metals (Pb2 $2^{+}$and $\left.\mathrm{Cd} 2^{+}\right)$on the Ultrastucture, Growth and Pigment Contents of the Unicellular Cyanobacterium Synechocystis sp. PCC 6803. Chinese Journal of Oceanology ang Limnology. 27(2): 383-388.

Barus, S.L. 2014. Keanekaragaman dan kelimpahan Perifiton di Perairan Sungai Deli Sumatera Utara. [Skripsi]. Universitas Sumatera Utara. Medan, hlm. 27-29.

Dahuri, R. 2003. Keanekaragaman Hayati Laut Aset Pembangunan Berkelanjutan Indonesia. Penerbitan Gramedia Pustaka Utama. Jakarta.

Fachrul, M.F. 2007. Metode Sampling Bioekologi. Bumi Aksara, Jakarta.

Herfina, Ruswahyuni, dan B. Sulardiono. 2014. Hubungan Kelimpahan Epifauna yang Berasosiasi dengan Lamun pada Tingkat Kerapatan Lamun yang Berbeda di Pantai Pulau Panjang, Jepara. Diponegoro Journal of Marquares III(1): 193-201.

Jaya, E. 2005. Struktur Komunitas Periphyton pada Tingkat Kerapatan Lamun (Thalassia) Berbeda di Perairan Pulau Panjang Jepara. Skripsi. Universitas Diponegoro. Semarang, hlm. 17-20.

KMNLH (Keputusan Menteri Negara Lingkungan Hidup). 2004. No.Kep51/2004 tentang Pedoman Penetapan Baku Mutu Air Laut, Kantor Menteri Negara Lingkungan Hidup, Jakarta.

Lestari dan Edward. 2004. Dampak Pencemaran Logam Berat Terhadap Kualitas Air Laut Dan Sumberdaya Perikanan (Studi Kasus Kematian Massal IkanIkan Di Teluk Jakarta).LIPI, Jakarta.

Mason, W.R.M. .1981. The polyphyletic nature of Apanteles Forester (Hymenoptera: Braconidae): a phylogeny and reclassification of Microgastrinae. Memoirs of the Entomological Society of Canada, 46p. 
Mayasari, D. 2008. Perbandingan Hasil Tangkapan Bubu pada Terumbu Buatan Bambu dan Ban di Sekitar Pulau Pramuka Kepulauan Seribu [Tesis]. Institut Pertanian Bogor. Bogor, hlm, 55.

Odum, E.P. 1971. Dasar-dasar Ekologi. Ed.2. W. B. Saunders Company. Philadelphia and London. Hlm. 574 (diterjemahkan oleh Samingan. T.).

Pescod, M. B. 1973. Investigation of Rational Effluent and Stream Standard For Tropical. AIT Bangkok. 43p.

Prakoso, K., Supriharyono, Ruswahyuni. 2015. Kelimpahan Epifauna di Substrat Dasar dan Daun Lamun Dengan Kerapatan yang Berbeda di Pulau Pahawang Provinsi Lampung. Diponegoro Journal of Maquares. 4 (3) : 11-122.

Prasetya, D. K., Ruswahyuni, Niniek W. 2015. Hubungan antara Kelimpahan Hewan Makrobenthos dengan Kerapatan Lamun yang Berbeda di Pulau Panjang dan Teluk Awyr Jepara. Diponegoro Journal of Marqueres. 4(4): 155-163.

Pratiwi., A, A. Pratomo, N. Willian. 2011. Analisis Kandungan Logam Berat Pb Dan Cd Terhadap Lamun (Enhalus Acoroides) Sebagai Bioindikator Di Perairan Tanjung Lanjut Kota Tanjungpinang. Universitas Mritim Raja Ali Haji. Hlm. 1-8.

Said, I., M.N. Jalaludin, A. Upe, dan A.W. Wahab. 2009. Penetapan konsentrasi logam berat krom dan timbal dalam sedimen estuaria sungai Matangpondo Palu. J. Chemica, 10(2):40-47.

SNI 06-6992.3-2004, Cara Uji timbal (Pb) secara Destruksi Asam dengan Spektofotometer Serapan Atom (SSA). Badan Standarisasi Nasional, Jakarta .

SNI 06-6992.4-2004, Cara Uji cadmium (Cd) secara Destruksi Asam dengan Spektofotometer Serapan Atom (SSA). Badan Standarisasi Nasional, Jakarta.

Tuwo, A. 2011. Pengelolaan Ekowisata Pesisir dan Laut. Surabaya, Brillian Internasional.

Wibowo., A. U dan D. Rosalina. 2014. Keanekaragaman Perifiton Pada Daun Lamun Di Pantai Tukak Kabupaten Bangka Selatan. Jurnal Sumberdaya Perairan. 8(2):17-26.

Yuniarno, H.A. 2015. Kelimpahan Perifiton pada Karang Masif dan Bercabang di Perairan Pulau Panjang, Jepara. Skripsi. Universitas Diponegoro. Semarang. Hlm. 38-41. 